\title{
PENGARUH PENGETAHUAN DAN SIKAP IBU TERHADAP PREVALENSI KARIES GIGI DI TK ISLAM AR - RAHMAN JLN. MEDAN - TG. MORAWA KECAMATAN TANJUNG MORAWA TAHUN 2014
}

\author{
Rawati Siregar \\ Jurusan Keperawatan Gigi Poltekkes Kemenkes Medan
}

\begin{abstract}
Abstrak
Status kesehatan anak sangat dipengaruhi oleh pengetahuan dan sikap ibu terhadap anaknya. Penelitian ini bertujuan untuk mengetahui pengaruh pengetahuan dan sikap ibu dengan prevalensi karies gigi anak di TK Islam Ar - Rahman Jln. Medan - Tg. Morawa Kecamatan Tanjung Morawa Tahun 2014.Penelitian ini bersifat analitik dengan rancangan Cross Sectional. Penelitian ini menggunakan uji Chi - square, pengolahan datanya dilakukan dengan menggunakan tabel Distribusi Frekuensi. Jumlah sampel adalah 25\% dari populasi yaitu 30 orang ibu dan siswa/i TK Islam Ar - Rahman. Data yang diperoleh adalah data primer dan sekunder. Data primer yaitu status karies gigi (def-t) yang diperoleh dengan pemeriksaan langsung pada rongga mulut siswa/I dan untuk mengetahui tingkat pengetahuan dan sikap ibu diperoleh dari kuesioner yang berisikan 25 pertanyaan.Hasil penelitian ini menunjukkan bahwa jumlah gigi yang diperiksa pada 30 siswa/i TK Islam Ar - Rahman adalah 595 gigi, rerata gigi susu yang terkena karies (d) sebesar 8,2, ekstraksi (e) sebanyak 0,2, dan def-t nya adalah 8,3. Tingkat pengetahuan ibu tentang kesehatan gigi dan mulut memiliki pengetahuan baik sebanyak $90 \%$ dan pengetahuan sedang sebanyak $10 \%$. Untuk tingkat sikap ibu terhadap kesehatan gigi dan mulut memiliki sikap positif sebanyak 96,66\% dan memiliki sikap negative sebanyak 3,33\%. Kesimpulan dari hasil penelitian ini yaitu untuk tingkat pengetahuan hipotesisnya (H0) diterima yang artinya tidak ada pengaruh pengetahuan yang signifikan antara pengetahuan ibu dengan prevalensi karies anaknya, sedangkan untuk sikap hipotesisnya (H0) diterima yang artinya pengaruh sikap ibu dengan status karies gigi anaknya tidak signifikan karena kemungkinan biasa dari banyak faktor lain seperti perilaku si anak tersebut dalam menjaga kesehatan gigi dan mulutnya.
\end{abstract}

Kata Kunci : Pengetahuan, Sikap, Prevalensi Karies Gigi

\section{A. Pendahuluan}

\section{Latar Belakang}

Dari hasil penelitian Anak pada hakikatnya merupakan asset terpenting dalam tercapainya keberhasilan suatu Negara, karena merupakan generasi penerus bangsa selanjutnya. Derajat kesehatan anak pada saat ini belum bisa dikatakan baik karena masih banyak terdapat masalah kesehatan khususnya pada anak pra sekolah. Anak usia pra sekolah merupakan kelompok usia yang kritis karena pada usia tersebut rentan terhadap masalah kesehatan. ( Gobel. 2009 ). Demikian pula dengan kesehatan gigi anak balita, anak balita yang juga termasuk anak pra sekolah juga perlu diperhatikan kesehatannya, khususnya kesehatan gigi, anak balita yang mengalami gigi berlubang pada gigi sulungnya dapat mempengaruhi pertumbuhan dan perkembangan gigi permanennya kelak. Untuk itu perlulah perawatan kesehatan gigi yang dilakukan orang tua secara rutin dengan memeriksakan gigi anak ke dokter gigi.

Perawatan gigi dan mulut pada masa balita / anak pra sekolah ternyata cukup menentukan kesehatan gigi dan mulut mereka pada tingkatan usia selanjutnya. Beberapa penyakit gigi dan mulut bisa mereka alami bila perawatan tidak dilakukan dengan baik. Di antaranya karies ( lubang pada permukaan gigi)Sampai saat ini, karies gigi masih menjadi masalah kesehatan anak. Organisasi Kesehatan Dunia (WHO) pada tahun 2003 menyatakan angka kejadian karies pada anak masih sebesar $60-90 \%$. Survey yang dilakukan oleh Departemen Kesehatan RepublikIndonesia menunjukkan prevalensi penduduk Indonesia yang menderita karies gigi sebesar $80 \%$, dimana $90 \%$ diantaranya adalah golongan umur anak balita. Menurut Antara News sebagaimana dikutip oleh Maulani dan Jubilee, (2005) jumlah balita di Indonesia mencapai $30 \%$ dari 250 juta penduduk Indonesia, sehingga diperkirakan balita yang mengalami kerusakan gigi mencapai 75 juta lebih. Penelitian yang dilakukan oleh peneliti Taverud (2009) menunjukkan bahwa prevalensi karies gigi pada anaksangat bervariasi jika didasarkan atas golongan umur dimana anak berusia 1 tahun sebesar $5 \%$, anak usia 2 tahun sebesar $10 \%$, anak usia 3 tahun sebesar $40 \%$, anak usia 4 tahun sebesar $55 \%$, dan anak usia 5 tahun sebesar $75 \%$. Dengan demikian golongan umur balita merupakan golongan rawan terjadinya karies gigi,memasuki usia pra sekolah resiko anak mengalami karies cukup tinggi. (tantursyah.blogspot.com). 
Di Indonesia laporan Survei Kesehatan Rumah Tangga (SKRT) DEPKES RI tahun 2001 menyatakan, diantara penyakit yang dikeluhkan dan yang tidak dikeluhkan prevalensi penyakit gigi dan mulut adalah tertinggi meliputi $60 \%$ penduduk. Berdasarkan Survei Kesehatan Rumah Tangga 2004, Situmorang (2005) menyatakan prevalensi karies di Indonesia mencapai 90,05\% dan ini tergolong lebih tinggi dibandingkan Negara berkembang lainnya. Karies menjadi bukti tidak terawatnya kondisi gigidan mulut masyarakat Indonesia (www.usu.ac.id).

Efrinda menyatakan memasuki usia pra sekolah resiko anak mengalami karies cukup tinggi, Pengetahuan dan sikap orang tua terutama ibu dalam pemeliharaan gigi memberi pengaruh cukup signifikanterhadap sikap dan perilaku anak dalam pemeliharaan kesehatan gigi. Disamping itu perilaku anak sendiri menentukan status kesehatan gigi mereka, termasuk pola makan dan kebutuhan membersihkan gigi. Pada umumnyan anak sangat menggemari makanan manis seperti permen dan coklat yang diketahui sebagai substrat dan disukai oleh bakteri yang selanjutnya dapat melarutkan struktur gigi. Keadaan ini diperburuk dengan kemalasan anak dalam membersihkan giginya. Terkadang ibu salah dalam mempersepsikan tentang karies gigi, karena kurangnya informasi dan pengalaman serta pemahaman yang didapatkan. Mereka beranggapan bahwa karies gigi merupakan suatu hal yang wajar dialami pada anak kecil dan hal ini tidak perlu untuk terlalu dikhawatirkan dan cenderung dianggap remeh karena jarang membahayakan jiwa. Ada beberapa ibu yang berpendapat karies gigi merupakan penyakit yang disebabkan karena seringnya anak memakan-makanan manis dan malas dalam menggosok gigi dengan ciri gigi berbercak hitam namun ada pulabeberapa orang ibu yang tidak mengerti apa yang disebut dengan karies dentis tersebut. Banyak ibu yang mengatakan bahwa perawatan gigi ini tidak terlalu penting untuk dilakukan dan hanya membuang uang saja sehingga mereka membiarkan anak mereka jika mengeluh sakit gigi namun jika sudah nampak parah baru mereka bawake klinik gigi. Hal ini seharusnya dapat menjadi perhatian dari tenaga kesehatan agar dapat memberikan penyuluhan pada masyarakat khususnya padapara ibu agar lebih mempedulikan kesehatan gigi anak mereka. (www.rumah kusorgaku. wordpress.com)

Dari studi pendahuluan yang dilakukan pada tanggal 10 Desember 2009 pada $10 \mathrm{ibu}$ yang memiliki anak usia 3 - 6 tahun di Desa Sumberjo Rembang yang dilakukan secara insidental,diketahui bahwa 9 ibu diantaranya memiliki anak yang menderita karies gigi. Kebanyakan dari ibu yang anaknya menderita karies gigi menyatakan bahwa selama ini tidak begitu merisaukan dengan kondisi karies gigi yang diderita anaknya. Mereka kebanyakan menyatakan tidak melakukan upayaupayauntuk mencegah terjadinya karies gigiseperti meminta anaknya agar tidak makan makanan yang mengandung kariogenik seperti gula-gula. Hal ini dilakukan karena menurut mereka lebih baik anaknya makan gula-gula dari pada tidak makan sama sekali.
Anak usia 2-4 tahun memilikikegemaran untuk makan makanan yang manis, sedangkan orang tua kurang mempedulikan kebiasaan untuk menyikat gigi, jika seorang anak tidak mau menggosok gigi maka sebagai orangtua sebaiknya dapat memaksa anaknya untuk menggosok gigi terutama saat menjelang tidurmalam. Bila seorang anak tidak terbiasa menggosok gigi maka dari kebiasaan tersebut dapat menyebabkan anak yang mengalami karies. Selain itu kebiasaan minum susu menjelang tidur dengan menggunakan susubotol yangterlalulama,jugakebiasaanmengulumpermen dan makan-makanan manis. (www.kalbe.co.id).

Hasil wawancara lebih lebih lanjut diperoleh data bahwa selama ini menurut para ibu tidak ada penyuluhan yang diberikan kepada warga tentang pentingnyakesehatan gigi bagi anak balita. Pengetahuan orang tua sangat penting dalam mendasari terbentuknya sikap yang mendukung atau tidak mendukung kebersihan gigi dan mulut anak. Pengetahuan tersebut dapat diperoleh secara alami maupun secara terencana yaitu melalui proses pendidikan. Orang tua dengan pengetahuan rendahmengenai kesehatan gigi dan mulut merupakan faktor predisposisi dari perilaku yang tidakmendukung kesehatan gigi dan mulut anak. Anak usia prasekolah (3-6 tahun) masih sangat bergantung pada orang tua dalam hal menjaga kebersihan dan kesehatan gigi. Pada umumnya, orang tua beranggapan bahwa anak usia prasekolah (3-6 tahun) sudah memiliki kemampuan yang cukup untuk membersihkan gigi, namun penting ditekankan kepada orang tua bahwa mereka harus terus membantu menyikat gigi anak-anak mereka.Anak usia prasekolah (3-6 tahun) dapat menyikat gigi mereka sendiri dengan dibantu oleh orang tua, setidaknya dua kali sehari dengan menggunakan pasta gigi berflouride seukuran kacang polong.

\section{Tujuan Penelitian}

Tujuan penelitian ini adalah untuk mengetahui pengaruh pengetahuan dan sikap ibu terhadap prevalensi karies gigi anak di TK Islam Ar-Rahman Tanjung Morawa.

\section{B. METODOLOGI PENELITIAN}

Penelitian ini menggunakan metode survey analitik dengan pendekatan Cross Sectional. Metode survey analitik atau penelitian yang mencoba menggali bagaimana dan mengapa fenomena kesehatan itu terjadi. Kemudian melakukan analisis dinamika korelasi antar fenomena, baik antara faktor resiko dengan faktor efek, antar faktor risiko maupun antar faktor efek.

Penelitian ini dilakukan di TK Islam Ar-Rahman Tanjung Morawa Kecamatan Tanjung Morawa Kabupaten Deli Serdang Propinsi Sumatera Utara. Penentuan lokasi penelitian dilatarbelakangi beberapa alasan yaitu :

Dilokasi penelitian ditemukan beberapa permasalahan kesehatan gigi terutama karies gigi pada kebanyakan siswanya.

Penelitian dilaksanakan mulai Maret 2014 sampai dengan Juli 2014. Populasi Penelitian ini adalah Ibu sebanyak 120 ibu dan siswa/i 120 anak 
Untuk menentukan sampel dalam penelitian ini, berpedoman pada pendapat Arikunto (2006:134) yang menyatakan bahwa, "Apabila subjek kurang 100 orang maka diambil semua. Sehingga penelitiannya disebut penelitian populasi, selanjutnya bila populasinya besar dapat diambil antara $10-15 \%$ dan 20-25\% lebih."Berdasarkan pendapat tersebut maka sampel diambil 25\% dari populasi, yaitu 30 orang siswa/i TK Islam Ar Rahman dan termasuk 30 orang responden (Ibu).

Pengambilan data dilakukkan dengan menggunakan instrument kuesioner .Kuesioner berisi 25 pertanyaan dimana 15 pertanyaan tentang pengetahuan ibu dan 10 pertanyaan tentang sikap ibu. Pada pertanyaan tentang pengetahuan bila jawaban benar diberi skor satu dan yang salah skor nol, dan pada pertanyaan tentang sikap diukur dengan skala likert, pilihan SS (Sangat Setuju) = 3, S (Setuju) =2, $\mathrm{R}($ Ragu $)=1$, TS $($ Tidak Setuju $)=0$.

Rentang nilai pengetahuan :

Rumus $=\underline{\text { nilai maksimum }- \text { nilai minimum }}$

$$
\begin{aligned}
& =\frac{15-0}{3} \\
& =5
\end{aligned}
$$

Penilaian pada akhir perhitungan adalah :

$\begin{array}{ll}\text { Buruk } & =0-5 \\ \text { Sedang } & =6-10 \\ \text { Baik } & =11-15\end{array}$

Rentang nilai sikap :

Rumus $=\underline{\text { nilai maksimum }- \text { nilai minimum }}$

$$
\begin{aligned}
& =\frac{30-0}{2} \\
& =15
\end{aligned}
$$

Penilaian pada akhir perhitungan adalah :

$$
\begin{array}{ll}
\text { Negatif } & =0-15 \\
\text { Positif } & =16-30 \\
& =3
\end{array}
$$

\section{HASIL DAN PEMBAHASAN}

Berdasarkan hasil penelitian yang dilakukan pada 30 siswa/i dan 30 responden yang merupakan ibu dari siswa/i TK Islam Ar - Rahman Jln. Medan - Tg. Morawa Kecamatan Tanjung Morawa Tahun 2014, maka diperoleh hasil sebagai berikut:

Tabel. 4.1.1 Distribusi frekuensi def-t siswa/i TK Islam Ar - Rahman Jln. Medan - Tg. Morawa Kecamatan Tanjung Morawa Tahun 2014

\begin{tabular}{ccccccc}
\hline \multirow{2}{*}{ Jumlah siswa/i } & \multirow{2}{*}{ Jumlah gigi susu } & \multicolumn{3}{c}{ Data def-t } \\
\cline { 3 - 7 } & & $\mathrm{D}$ & $\mathrm{E}$ & $\mathrm{f}$ & $\mathrm{def}-\mathrm{t}$ \\
\hline 30 & 595 & 245 & 5 & 0 & 250 \\
\hline \multicolumn{2}{c}{ Rata - rata } & 8.2 & 0.2 & 0 & 8.3 \\
\hline
\end{tabular}

Berdasarkan tabel diatas terlihat bahwa dari 30 siswa/i dengan jumlah gigi susu sebanyak 595 gigi, rata - rata gigi susu yang terkena karies (d) sebanyak 8,2, ekstraksi (e) sebanyak 0,2 dan def-t nya adalah 8,3.

Tabel.4.1.2 Distribusi frekuensi pengetahuan responden tentang Kesehatan Gigi dan Mulut pada TK Islam Ar Rahman Jln. Medan - Tg. Morawa Kecamatan Tanjung Morawa Tahun 2014.

\begin{tabular}{cccc}
\hline No. & Kategori Pengetahuan & Frekuensi & Persentase (\%) \\
\hline 1. & Baik & 27 & 90 \\
2. & Sedang & 3 & 10 \\
3. & Buruk & 0 & 0 \\
\hline & Jumlah & 30 & 100 \\
\hline
\end{tabular}

Berdasarkan tabel diatas terlihat bahwa pengetahuan ibu tentang kesehatan gigi dan mulut 90\% memiliki pengetahuan yang baik dan $10 \%$ memiliki pengetahuan sedang.

Tabel.4.1.3 Distribusi frekuensi sikap responden tentang Kesehatan Gigi dan Mulut pada TK Islam Ar Rahman Jln. Medan - Tg. Morawa Kecamatan Tanjung Morawa Tahun 2014.

\begin{tabular}{cccc}
\hline No. & Kategori Sikap & Frekuensi & Persentase (\%) \\
\hline 1. & Positif & 29 & 96,66 \\
2. & Negatif & 1 & 3,33 \\
\hline & Jumlah & 30 & 100 \\
\hline
\end{tabular}

Berdasarkan tabel diatas terlihat bahwa sikap ibu tentang Kesehatan Gigi dan Mulut 96,66\% memiliki sikap positif dan 3,33\% memiliki sikap negatif. 
Tabel.4.1.4 Uji Chi Square pengaruh pengetahuan ibu terhadap prevalensi karies anaknya Menggunakan tabel $3 \times 2$

\begin{tabular}{ccccc}
\hline \multirow{2}{*}{ Tingkat Pengetahuan } & \multicolumn{2}{c}{ def-t } & \multirow{2}{*}{ Jumlah } \\
\cline { 2 - 4 } & $\leq 2$ & 25 & 27 \\
\hline Baik & 2 & 3 & 3 \\
\hline Sedang & 0 & 0 & 0 \\
\hline Buruk & 0 & 28 & 30 \\
\hline Jumlah & 2 & 25 & 3
\end{tabular}

\section{Nilai ekspektasi}

$\begin{array}{llll}\text { b1.k1 } & :(2+25)(2+0+0) / 30 & =54 / 30=1,8 & \\ \text { b1.k2 } & :(2+25)(25+3+0) / 30 & =756 / 30=25,2 & \\ \text { b2.k1 } & :(0+3)(2+0+0) / 30 & =6 / 30 & =0,2 \\ \text { b2.k2 } & :(0+3)(25+3+0) / 30 & =84 / 30=2,8 & \\ \text { b3.k1 } & :(0+0)(2+0+0) / 30 & =0 / 30 & =0 \\ \text { b3.k2 } & :(0+0)(25+3+0)=0 / 30 & & =0\end{array}$

\begin{tabular}{|c|c|c|c|c|c|}
\hline Cel & $\mathrm{O}$ & $\mathrm{E}$ & $\mathrm{O}-\mathrm{E}$ & $(\mathrm{O}-\mathrm{E})^{2}$ & $(\mathrm{O}-\mathrm{E})^{2 / \mathrm{E}}$ \\
\hline b1.k1 & 2 & 1,8 & 0,2 & 0,04 & 0,022 \\
\hline b1.k2 & 25 & 25,2 & $-0,2$ & 0,04 & 0,001 \\
\hline b2.k1 & 0 & 0,2 & $-0,2$ & 0,04 & 0,2 \\
\hline b2.k2 & 3 & 2,8 & 0,2 & 0,04 & 0,014 \\
\hline b3.k1 & 0 & 0 & 0 & 0 & 0 \\
\hline b3.k2 & 0 & 0 & 0 & 0 & 0,237 \\
\hline \multicolumn{7}{|r|}{}
\end{tabular}

Tabel.4.1.5 Uji Chi Square pengaruh sikap ibu terhadap prevalensi karies anaknya menggunakan tabel 2x2

\begin{tabular}{|c|c|c|c|}
\hline \multirow[b]{2}{*}{ Kategori Sikap } & \multicolumn{2}{|c|}{ def-t } & \multirow[b]{2}{*}{ Jumlah } \\
\hline & $\leq 2$ & $\geq 2$ & \\
\hline Positif & 2 & 27 & 29 \\
\hline Negatif & 0 & 1 & 1 \\
\hline Jumlah & 2 & 28 & 30 \\
\hline
\end{tabular}

\section{Nilai ekspektasi}

$\begin{array}{llll}\text { b1.k1 } & :(2+27)(2+0) / 30 & =58 / 30 & =1,93 \\ \text { b1.k2 } & :(2+27)(27+1) / 30 & & =812 / 30=27,06 \\ \text { b2.k1 } & :(0+1)(2+0) / 30 & =2 / 30 & =0,06 \\ \text { b2.k2 } & :(0+1)(27+1) / 30 & =28 / 30 & =0,93\end{array}$

\begin{tabular}{|c|c|c|c|c|c|}
\hline Cel & $\mathrm{O}$ & $\mathrm{E}$ & $\mathrm{O}-\mathrm{E}$ & $(\mathrm{O}-\mathrm{E})^{2}$ & $(\mathrm{O}-\mathrm{E})^{2} / \mathrm{E}$ \\
\hline b1.k1 & 2 & 1,93 & 0,07 & 0,0049 & 1,63 \\
\hline b1.k2 & 27 & 27,06 & $-0,06$ & 0,0036 & 0,00012 \\
\hline b2.k1 & 0 & 0,06 & $-0,06$ & 0,0036 & 0,00012 \\
\hline b2.k2 & 1 & 0,93 & 0,07 & 0,0049 & 1,63 \\
\hline \multicolumn{7}{|l|}{$\mathrm{X}^{2}$ hitung } & 3,260 \\
\hline
\end{tabular}

\section{Pembahasan}

Berdasarkan penelitian pada 30 siswa/i TK Islam Ar - Rahman Jln. Medan - Tg. Morawa Kecamatan Tanjung Morawa, didapatkan bahwa dari 595 gigi susu yang diperiksa, rata - rata yang terkena karies sebesar 8,3. Angka ini menunjukkan bahwa angka karies pada siswa/i tersebut lebih tinggi dari target pencapaian, dimana target def-t menurut WHO adalah $\leq 2$.

Dari hasil penelitian yang dilakukan di TK Islam $\mathrm{Ar}$ - Rahman dengan responden adalah ibu dari siswa/i TK Islam $\mathrm{Ar}$ - Rahman diketahui tingkat pengetahuan dari 30 orang responden (ibu) tentang kesehatan gigi dan mulut
90\% memiliki pengetahuan baik dan 10\% memiliki pengetahuan sedang.

Sedangkan untuk tingkat sikap dari 30 orang responden (ibu) tentang kesehatan gigi dan mulut yaitu 96,66\% memiliki sikap positif dan 3,33\% memiliki sikap negatif.

Kemudian data diolah dengan uji statistik dengan cara manual dengan tujuan untuk mengetahui pengaruh pengetahuan dan sikap para ibu terhadap prevalensi karies gigi anaknya di TK Islam Ar - Rahman Jln. Medan - Tg. Morawa Kecamatan Tanjung Morawa Tahun 2014 dengan menggunakan uji Chi- square dengan tingkat signifikan $\propto$ $=5 \%$ dengan analisa hipotesis sebagai berikut : 
H0 : Ada pengaruh yang signifikan antara pengetahuan ibu terhadap prevalensi karies gigi pada anak Hipotesis diterima : $\mathrm{X}^{2}$ hitung $<\mathrm{X}^{2}$ tabel Hipotesis ditolak : $\mathrm{X}^{2}$ hitung $>\mathrm{X}^{2}$ tabel Dimana :

- $\quad \mathrm{X}^{2}$ hitung $=\sum(O-E)^{2}($ Perhitungan Chi-square )

E

- $\quad \mathrm{X}^{2}$ tabel $=($ Tabel nilai kritis distibusi Chisquare )

- $\mathrm{df} \quad=(\mathrm{b}-1)(\mathrm{k}-1)($ derajat kebebasan )

$$
\begin{aligned}
& =(3-1)(2-1) \\
& =2
\end{aligned}
$$

- derajat kepercayaan $\quad=95 \%$

berdasarkan tabel Tabel.4.1.4 nilai distribusi Chi Square pengaruh pengetahuan ibu sebesar 0,237 dengan df (derajat kebebasan) adalah 2 serta derajat kepercayaan 95\% sehingga didapat $\mathrm{X}^{2}$ sebesar 5,991.

Dilihat dari daerah kritis bahwa :

$\begin{array}{lll}\mathrm{X}^{2} \text { hitung } & < & \mathrm{X}^{2} \text { tabel } \\ 0,237 & < & 5,991\end{array}$

Dengan demikian apabila H0 diterima artinya “ tidak ada pengaruh yang signifikan antara pengetahuan ibu dengan prevalensi karies gigi anaknya di TK Islam $\mathrm{Ar}$ - Rahman Jln. Medan - Tg. Morawa Kecamatan Tanjung Morawa Tahun 2014 “. Hal ini sama dengan penelitian Syahri (2011) yang menunjukkan tidak ada hubungan pengetahuan ibu dengan def-t.

Sedangkan untuk pengaruh sikap responden (ibu) dapat dilihat dari Tabel 4.1.5 dengan tingkat signifikan $\propto=$ 5\% dengan analisa hipotesis sebagai berikut :

H0 : Ada pengaruh yang signifikan antara sikap ibu terhadap prevalensi karies gigi pada anak

Dimana :

- $\quad \mathrm{X}^{2}$ hitung Chi-square )

$$
=\sum(O-E)^{2}(\text { Perhitungan }
$$

$$
\text { E }
$$

- $\quad \mathrm{X}^{2}$ tabel $=($ Tabel nilai kritis distibusi Chisquare )

- $\mathrm{df}$ kebebasan )

$$
=(\mathrm{b}-1)(\mathrm{k}-1)(\text { derajat }
$$

$$
\begin{aligned}
& =(2-1)(2-1) \\
& =1
\end{aligned}
$$

- derajat kepercayaan

$$
=95 \%
$$

Berdasarkan tabel Tabel.4.1.5 nilai distribusi Chi Square pengaruh sikap ibu sebesar 3,260 dengan df (derajat kebebasan) adalah 1 serta derajat kepercayaan 95\% sehingga didapat $\mathrm{X}^{2}$ sebesar 3,841.

Dilihat dari daerah kritis bahwa :

$\begin{array}{lll}\mathrm{X}^{2} \text { hitung } & < & \mathrm{X}^{2} \text { tabel } \\ 3,260 & < & 3,841\end{array}$

Dengan demikian apabila H0 diterima artinya “ tidak ada pengaruh yang signifikan antara sikap ibu dengan prevalensi karies gigi anaknya di TK Islam Ar - Rahman Jln. Medan - Tg. Morawa Kecamatan Tanjung Morawa Tahun 2014 “. Hal ini disebabkan karena dilihat dari hasil penelitian hanya 2 orang siswa/i dari 30 orang yang angka def-t nya masih dibatas normal yaitu $\leq 2$.

Dengan demikian dapat disimpulkan bahwa prevalensi karies gigi tidak hanya dipengaruhi oleh pengetahuan dan sikap ibu terhadap kesehatan gigi akan tetapi dari banyak faktor lain seperti faktor etiologi, perilaku atau tindakan yang dilakukan oleh si anak tersebut dalam menjaga kesehatan gigi dan mulutnya (Herijulianti dkk, 2002).

\section{KESIMPULAN}

Berdasarkan penelitian serta pembahasan yang dilakukan, dapat dikemukakan suatu hasil sebagai kesimpulan, yaitu :

1 Rata - rata def-t siswa/i TK Islam Ar - Rahman Jln. Medan - Tg. Morawa Kecamatan Tanjung Morawa Tahun 2014 adalah 8,3. Angka ini menunjukkan bahwa angka karies pada siswa/i tersebut lebih tinggi dari target pencapaian, dimana target def-t menurut WHO adalah $\leq 2$

2 Pengetahuan ibu mengenai kesehatan gigi dan mulut pada siswa/i TK Islam Ar - Rahman Jln. Medan - Tg. Morawa Kecamatan Tanjung Morawa Tahun 2014 yang berjumlah 30 orang, 90\% memiliki pengetahuan yang baik dan $10 \%$ memiliki pengetahuan sedang.

3 Sikap ibu mengenai kesehatan gigi dan mulut pada siswa/i TK Islam Ar - Rahman Jln. Medan - Tg. Morawa Kecamatan Tanjung Morawa Tahun 2014 yaitu 96,66\% memiliki sikap positif dan 3,33\% memiliki sikap negative terhadap kesehatan gigi dan mulut anak.

4 Tidak ada pengaruh pengetahuan dan sikap ibu terhadap prevalensi karies gigi anak di TK Islam Ar - Rahman Jln. Medan - Tg. Morawa Kecamatan Tanjung Morawa Tahun 2014, hal ini dilihat dari hasil uji statistic dengan uji Chi-square didapatkan hasil hipotesinya (H0) diterima, dengan begitu dapat dikatakan pengetahuan dan sikap ibu tidak berpengaruh terhadap status karies gigi anaknya kemungkinan ada faktor lain.

\section{SARAN}

1. Bagi orang tua terutama ibu siswa/i TK Islam Ar Rahman Jln. Medan - Tg. Morawa Kecamatan Tanjung Morawa Tahun 2014 agar dapat lebih memperhatikan dan membimbing anaknya untuk menjaga kesehatan gigi dan mulutnya karena ibu merupakan orang yang paling dekat dan mengerti anak agar kesehatan gigi anak menjadi lebih meningkat dan lubang atau karies pada gigi bisa berkurang di masa depan saat anak sudah dewasa.

2. Bagi pihak sekolah TK Islam Ar - Rahman Jln. Medan - Tg. Morawa Kecamatan Tanjung Morawa agar lebih meningkatkan upaya dalam hal kesehatan gigi dan mulut siswa/i TK Islam Ar - Rahman dan bisa bekerja sama dengan puskesmas setempat. 
3. Bagi siswa/i TK Islam Ar - Rahman Jln. Medan Tg. Morawa Kecamatan Tanjung Morawa dianjurkan agar menjaga kesehatan gigi dan mulutnya dengan memeriksakan giginya minimal 6 bulan sekali ke dokter gigi atau ke klinik gigi, menyikat gigi 2 x sehari pagi setelah sarapan dan malam sebelum tidur, juga berkumur - kumur atau menyikat gigi setelah makan - makanan manis seperti permen dan coklat.

\section{DAFTAR PUSTAKA}

Alwi, Hasan. 2002. Kamus Besar Bahasa Indonesia.Jakarta : Balai Pustaka.

Anas, Muhammad. 2007.Pengantar Psikologi Sosial. Makassar : Badan Penerbit UNM

Arikunto, Suharsimi. 2006.Prosedur Penelitian Suatu Pendekatan Praktik. Jakarta : Rineka Cipta.

Edwina \& sally Joyston - Bechal. 1991. Dasar - Dasar Karies penyakit dan Penanggulangannya. (terjemahan : Narlan Sumawinata \& Safrida Faruk). Jakarta : EGC
Notoatmodjo, Soekidjo. 2010.Metodologi Penelitian Kesehatan. Jakarta : Rineka Cipta

Salam, Burhanuddin. 2003. Pengantar Filsafat. Jakarta: Bumi Aksara.

Sugiyono. 2011.Metode Penelitian Kuantitatif Kualitatif. Bandung : Alfabeta.

Surakhmad, Winarno. 2000.Pengantar Penelitian Ilmiah dan DasarMetode Teknik. Bandung : Transito.

Syahri. 2011, Hubungan Pendidikan dan Pengetahuan Para Ibu Dengan Status Karies Gigi Balitanya Di PAUD Sekar Mayang. KTI. Medan.

Tarigan, Rasinta. 1990. Karies Gigi. Jakarta : Hipokrates.

Widi, Restu Kartiko. 2010. Asas Metodologi Penelitian. Yogyakarta : Graha Ilmu.

www.kalbe.co.id. Diakses tanggal 22 April 2014

www.lintas.me/publisher/tantursyah.blogspotcom. Diakses tanggal 22 April 2014

www.usu.ac.id/diglib/

www.rumahkusorgaku.wordpress.com.Diakses tanggal 22 April 2014 